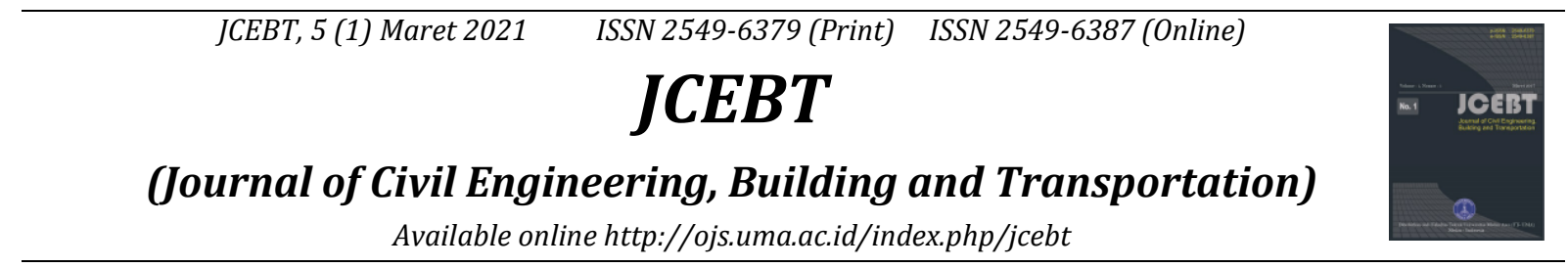

\title{
Evaluasi Tingkat Kerusakan Jalan Sebagai Dasar Penentuan Perbaikan Jalan
}

\section{Evaluation of the Level of Damage to the Road as a Basis for Determining Road Improvemen}

\author{
Khamdan Muhajir , Rasio Hepiyanto \\ Teknik Sipil, Fakultas Teknik, Universitas Islam lamongan, Indonesia \\ *Coresponding Email: Khamdanmuhaiir@gmail.com
}

\begin{abstract}
ABSTRAK
Penurunan kualitas jalan mengakibatkan terjadinya kerusakan jalan. Hal tersebutlah yang membuat peneliti ingin mengetahui kondisi jalan sugio-kedungpring untuk menganalisis kerusakannya menggunakan metode PCI. Dilakukannya penelitian ini yaitu untuk mengetahui kondisi jalan yang mengalami kerusakan sebagai dasar acuan untuk perbaikan jalan agar jalan tersebut dapat berfungsi dengan layak. Penelitian akan dilakukan dengan pengumpulan data primer berupa jenis kerusakan jalan, luasan kerusakan jalan tingkat kerusakan dan lain-lain yang didapat dengan cara survei di lapangan, serta data sekunder berupa tinjauan literatur dan curah hujan harian dengan cara studi dokumen, setelah itu data akan dianalisis menggunakan metode PCI dan didapat kesimpulan jenis kerusakan jalan didominasi dengan kerusakan retak kulit buaya dengan nilai kondisi perkerasan sebesar 53,952. Dilakukannya penelitian ini bertujuan untuk mengetahui dominasi kerusakan jalan, dan besaran nilai kondisi perkerasan jalan di jalan sugio-kedungpring.
\end{abstract}

Kata Kunci: Kerusakan Jalan, PCI, Kabupaten Lamongan.

\begin{abstract}
Decreased road quality results in road damage. This is what makes researchers want to know the sugiokedungpring road conditions to analyze the damage using the PCI method. This research is conducted to find out the condition of the damaged road as a reference base for road repairs so that the road can function properly. The research will be carried out by collecting primary data in the form of types of road damage, the extent of damage to the level of damage and others obtained by survey in the field, as well as secondary data in the form of literature review and daily rainfall using document studies, after which the data will be analyzed using the PCI method and the conclusion that the type of road damage is dominated by crocodile crack damage with a value of pavement conditions of 53.952. The purpose of this research is to find out the dominance of road damage, and the magnitude of the value of road pavement conditions on the sugio-kedungpring road.
\end{abstract}

Keywords: Road Damage, PCI, Lamongan Regency

How to Cite: Khamdan Muhajir, Rasio Hepiyanto. (2020). Evaluasi Tingkat Kerusakan Jalan Sebagai Dasar Penentuan Perbaikan Jalan. JCEBT (Journal of Civil Engineering, Building and Transportation). 5(1): 46-55 


\section{PENDAHULUAN}

Jalan raya merupakan salah satu prasarana transportasi darat yang sangat penting dalam aspek kegiatan manusia. Kondisi jalan diharapkan dapat memberikan rasa aman dan nyaman bagi pengguna prasarana jalan raya. Kondisi jalan yang baik akan mempengaruhi mobiltas manusia dalam melakukan berbagai aktivitas. Namun seiring meningkatnya jumlah penduduk di daerah Lamongan, maka kebutuhan sarana transportasi juga meningkat sehingga menyebabkan terjadinya penurunan kualitas jalan raya. Hal ini di sebabkan karena prasarana (jalan) yang terbebani oleh volume lalu lintas yang tinggi dan terjadi berulang-ulang.

Prasarana jalan yang terbebani oleh volume lalu lintas yang tinggi dan berulang-ulang akan menyebabkan terjadi penurunan kualitas jalan. Sebagai indikatornya dapat diketahui dari kondisi permukaan jalan, baik kondisi struktural maupun fungsionalnya yang mengalami kerusakan. Suatu penelitian tentang bagaimana kondisi permukaan jalan dan bagian jalan lainnya sangat diperlukan untuk mengetahui kondisi permukaan jalan yang mengalami kerusakan tersebut. Penelitian awal terhadap kondisi permukaan jalan tersebut yaitu dengan melakukan survei secara visual yang berarti dengan cara melihat dan menganalisis kerusakan tersebut berdasarkan jenis dan tingkat kerusakannya untuk digunakan sebagai dasar dalam melakukan kegiatan pemeliharaan dan perbaikan.

Oleh karena itu dalam penelitian ini, peneliti akan mencoba menganalisis kerusakan jalan sugio-kedungpring dengan menggunakan metode PCI sebagai dasar untuk solusi dari perbaikannya, dengan tujuan kerusakan jalan sugiokedungpring tersebut dapat teridentifikasi besaran nilai kerusakannya agar dapat dicari solusi penanganan dan perbaikannya.

Kerusakan jalan disebabkan antara lain karena beban lalu lintas berulang yang berlebihan (Overload), panas atau suhu udara, air dan hujan, serta mutu awal produk jalan yang jelek. Oleh sebab itu disamping direncanakan secara tepat jalan harus dipelihara dengan baik agar dapat melayani pertumbuhan lalu lintas selama umur rencana. Pemeliharaan jalan rutin maupun berkala perlu dilakukan untuk mempertahankan keamanan dan kenyamanan jalan bagi pengguna dan menjaga daya tahan atau keawetan sampai umur rencana. (Suwardo dan Sugiharto, 2004).

Survei kondisi perkerasan perlu dilakukan secara periodik baik struktural 
maupun nonstruktural untuk mengetahui tingkat pelayanan jalan yang ada. Pemeriksaan nonstruktural (fungsional) antara lain bertujuan untuk memeriksa kerataan (roughness), kekasaran (texture), dan kekesatan (skid resistance). Pengukuran sifat kerataan lapis permukaan jalan akan bermanfaat di dalam usaha menentukan program rehabilitasi dan pemeliharaan jalan. Di Indonesia pengukuran dan evaluasi tingkat kerataan jalan belum banyak dilakukan salah satunya dikarenakan keterbatasan peralatan. Karena kerataan jalan berpengaruh pada keamanan dan kenyamanan pengguna jalan maka perlu dilakukan pemeriksaan kerataan secara rutin sehingga dapat diketahui kerusakan yang harus diperbaiki. (Suwardo dan Sugiharto, 2004).

Penilaian tipe dan kondisi permukaan jalan yang ada merupakan aspek yang paling penting dalam penentuan sebuah proyek, sebab karakteristik inilah yang akan menentukan satuan nilai manfaat ekonomis yang ditimbulkan oleh adanya perbaikan jalan.

PCI adalah sistem penilaian kondisi perkerasan jalan berdasarkan jenis, tingkat dan luas kerusakan yang terjadi serta dapat digunakan sebagai acuan dalam usaha pemeliharaan. Tiga tingkat kerusakan yang dapat diidentifikasi oleh metode PCI (Shahin, 1994), yaitu:

1. jenis kerusakan (distress type), yaitu jenis-jenis kerusakan yang secara visual dapat terlihat di permukaan perkerasan. Jenis-jenis kerusakan terbagi atas 19 jenis;

2. tingkat kerusakan (distress severity), yaitu jenis kerusakan yang diidentifikasi sesuai kondisi tipe kerusakan. Tingkat kerusakan ini terbagi atas low (1), medium (m), high (h);

3. jumlah kerusakan (distress amount), berkaitan dengan pengukuran, satuan pengukuran, dan penjumlahan (total) pada formulir survei pada masing-masing tingkat kerusakan.

Pengertian dan istilah-istilah berdasarkan tahapan-tahapan perhitungan pada metode PCI (Lukman, 2014).

(1) Survei pendahuluan Survei pendahuluan merupakan survei yang harus dilakukan pada awal kegiatan, yaitu sebelum survei detail karena survei detail akan mengacu pada hasil survei. Survei pendahuluan bertujuan untuk mengetahui kondisi umum perkerasan, data geometri, dan jenis-jenis kerusakan yang sering terjadi di lapangan.

(2) Pembagian unit sampel Unit sampel dibagi dalam beberapa unit. Hal ini dilakukan untuk mempermudah dalam pelaksanaan perhitungan dan pengolahan 
data. Inspeksi dari setiap unit sampel dalam suatu bagian perkerasan yang membutuhkan usaha ekstra, khususnya jika bagiannya besar. Pembagian unit sampel dihitung mengggunakan Persamaan (a).

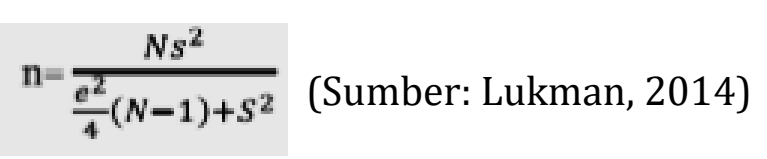

\section{Dengan:}

$\mathrm{n}=$ Jumlah unit sampel

$\mathrm{N}=$ Jumlah total unit sampel dalam suatu bagian perkerasan

$\mathrm{e}=$ Kesalahan yang diizinkan dalam estimasi dari bagian PCI ( $\mathrm{e}=5)$,

$\mathrm{s}=$ Deviasi standar antara unit sampel di dalam bagiannya (untuk $\mathrm{AC}, \mathrm{s}=10$ ) Setelah didapatkan jumlah minimum dari unit sampel, ditentukam jarak interval tiap sampel yang dihitung menggunakan Persamaan (b).

$$
i=\frac{N}{n} \quad \text { Sumber: ASTM D5340-12, }
$$

\section{Dengan:}

$\mathrm{N}=$ Jumlah total unit sampel satu bagian perkerasan

$\mathrm{n}=$ Jumlah unit sampel minimum

$\mathrm{i}=$ Interval jarak unit-unit sampel

\section{a. Density}

Density atau kadar kerusakan adalah persentase kerusakan terhadap luasan suatu unit segmen yang diukur meter persegi atau meter panjang. Nilai density suatu jenis kerusakan dibedakan juga berdasarkan tingkat kerusakannya. Nilai density dihitung menggunakan Persamaan (c) atau Persamaan (d).

Density $=\frac{A d}{A s} \times 100$ (Sumber: Lukman, 2014)

atau dengan

Density $=\frac{L d}{A s} \times 100$ (Sumber: Lukman, 2014)

Ad $=$ Luas total jenis kerusakan untuk tiap tingkat kerusakan (m2)

Ld = Panjang total jenis kerusakan untuk tiap tingkat kerusakan (m)

As $=$ Luas total unit segmen $(\mathrm{m} 2)$

b. Deduct Value Deduct value merupakan nilai pengurangan pada setiap jenis kerusakan yang diperoleh dari hubungan antara density dan deduct value.

c.. Total Deduct Value

Total deduct value (TDV) merupakan nilai total dari individual deduct value untuk tiap jenis kerusakan dan tingkat kerusakan yang ada pada suatu unit penelitian.

\section{d.. Corrected Deduct Value \\ Corrected deduct value} (CDV) merupakan nilai yang diperoleh dari kurva hubungan antara nilai TDV dan nilai CDV dengan pemulihan lengkung kurva sesuai dengan jumlah nilai setiap deduct value yang mempunyai nilai lebih besar dari 2 . 
e. Nilai Allowable Number of Deduct

Nilai allowable number of deduct (m) adalah maksimum nilai deduct setiap jenis perkerasan yang diizinkan untuk diperhitungkan di dalam penilaian kondisi perkerasan.

\section{f. Menentukan Kondisi Perkerasan}

Nilai PCI yang didapatkan kemudian diplot ke dalam diagram nilai PCI sehingga didapatkan kategori kondisi perkerasan pada unit sampel tersebut. Diagram nilai PCI dapat dilihat pada Gambar 1.

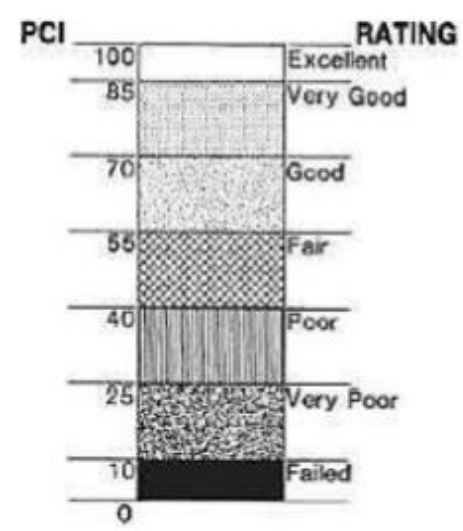

Gambar 1. Rating Kondisi Jalan Berdasarkan Metode PCI

Sumber: Shahin, 1994

\section{METODE PENELITIAN}

Penelitian ini yaitu menggunakan metode penelitian kuantitatif adalah metode penelitian yang mengunakan proses data-data yang berupa angka sebagai alat menganalisis dan melakukan kajian penelitian, terutama mengenai apa yang sudah diteliti. Dalam penelitian ini, rancangan penelitiannya akan menggunakan data-data yang berupa angka-angka tingkat kerusakan jalan pada sugio-kedungpring yang didapat dengan cara pengumpulan yaitu survei dilapangan dan juga dengan study pustaka lalu data yang telah terkumpul tersebut akan dianalisis menggunakan metode PCI hingga mendapatkan kesimpulan yang dapat menjawab rumusan masalah.

\section{HASIL DAN PEMBAHASAN}

\section{Deskripsi Objek Penelitian}

Tempat penelitian akan dilakukan di Jalan Kedungpring - Sugio Kab. Lamongan. Dalam penelitian ini hanya dilakukan 1 ruas jalan yang telah ditentukan dengan panjang $500 \mathrm{~m}$ persegmenya. Ruas jalan ini termasuk ruas jalan kecamatan Kedungpring - Sugio. Peneliti mengambil panjang jalan yang diteliti 500 m dari jalan Kedungpring sampai Sugio. Tepatnya berada pada Jl. Desa Telanak.

Analisis Data Menggunakan Metode PCI (Pavement Condition Index) Dari data hasil penelitian didapatkan nilai kondisi jalan pada setiap ruas jalan yang diteliti dan dibagi kedalam beberapa bagian. Berikut langkah-langkah dalam perhitungan analisis data.

Volume Lalu-lintas Jalan Kendaraan/Jam SMP/Jam

1. Sepeda Motor (MC) 0.42 710.67 298.48

2. Kendaraan Ringan (LV) 1.0056 .92 56.92.

a. Penentuan Jumlah Unit Sampel 
Pemilihan jumlah minimum unit sampel yang harus disurvei. Nilai standar deviasi untuk perkerasan yang diteliti adalah $8-10$ dengan kisaran PCI 20 - 25. Luasan unit sampel harus diantara $232 \pm 93 \mathrm{~m} 2$. Peneliti menentukan luasan yang disurvei $140 \mathrm{~m} 2$ dengan lebar jalan rata-rata 5,6 m. Didapat panjang jalan per unit sampel $=25$ m. Pada setiap ruas jalan yang diteliti dengan panjang total $800 \mathrm{~m}$ dibagi setiap 1 unit sampel panjangnya $25 \mathrm{~m}$, sehingga jumlah unit sampel yang tersedia $=32$ unit sampel $25 \mathrm{~m}$. dan diketahui jumlah total unit sampel $(\mathrm{N})=32$, sehingga didapat jumlah minimum unit sampel yang disurvei adalah 10 , maka, $=3,2$ dibulatkan ke bawah = 3 Interval jarak unit sampel adalah 3, diperoleh jumlah unit sampel yang disurvei 10 .

Tabel 1. Luasan Unit Sampel

\begin{tabular}{|c|c|c|c|c|}
\hline No. & Unit Sampel & $\begin{array}{c}\text { Panjang } \\
(\mathrm{m})\end{array}$ & Lebar $(\mathrm{m})$ & $\begin{array}{c}\text { Luasan Unit } \\
\text { Sampel }\left(\mathrm{m}^{2}\right)\end{array}$ \\
\hline 1 & A1 & 25 & 5.6 & 140 \\
\hline 2 & A2 & 25 & 5.6 & 140 \\
\hline 3 & A3 & 25 & 5.6 & 140 \\
\hline 4 & A4 & 25 & 5.6 & 140 \\
\hline 5 & A5 & 25 & 5.6 & 140 \\
\hline 6 & A6 & 25 & 5.6 & 140 \\
\hline 7 & A7 & 25 & 5.6 & 140 \\
\hline 8 & A8 & 25 & 5.6 & 140 \\
\hline 9 & A9 & 25 & 5.6 & 140 \\
\hline 10 & A10 & 25 & 5.7 & 142.5 \\
\hline
\end{tabular}

Sumber : Hasil Perhitungan Penelitian, 2020

b. Penentuan Deduct Value (DV)

Dalam menentukan nilai DV ini digunakan contoh perhitungan pada ruas jalan Sugio - Kedungpring (A). Adapun langkah-langkah menentukan DV sebagai berikut.

1. Diberikan contoh pada ruas $\mathrm{A}$, unit sampel A1, jenis kerusakan pelapukan dan butiran lepas (19) tingkat kerusakan rendah (L), menjumlahkan angka pada setiap tingkat keparahan kerusakan, dan mencatat pada kolom "Total" pada formulir survei. Pada kolom Banyaknya, kerusakan 0,36 (artinya, luasan pelapukan dan butiran lepas 0,36 m2 ) dan jumlahnya dimasukan dalam kolom "Total" yaitu nilai 0,36 yang berarti luasan total pelapukan dan butiran lepasnya 0,36 m2 . Satuan pada tiap jenis kerusakan dapat berupa $m, m 2$, atau angka, tergantung pada jenis kerusakan.

2. Persentase kerapatan per sampel Diberikan contoh pada ruas jalan $\mathrm{A}$, unit sampel A1, jenis kerusakan pelapukan dan butiran lepas (19) tingkat kerusakan rendah (L), didapat dari pembagian total ukuran dari setiap tipe kerusakan pada setiap tingkat keparahan kerusakan dengan luas total dari unit sampel (area sampel). Lalu dikalikan dengan 100. Misalnya pada sampel didapatkan luasan total pelapukan dan butiran lepas 0,36 $\mathrm{m} 2$, dan luas unit sampel $140 \mathrm{~m} 2$, maka kerapatan kerusakan adalah $=0,26 \%$. 


\section{c. Penentuan DV Sesuai Grafik}

Diberikan contoh pada ruas A, unit sampel A1, jenis kerusakan pelapukan dan butiran lepas (19) tingkat kerusakan rendah (L). Untuk memperoleh DV digunakan grafik nilai DV pada Gambar berikut.

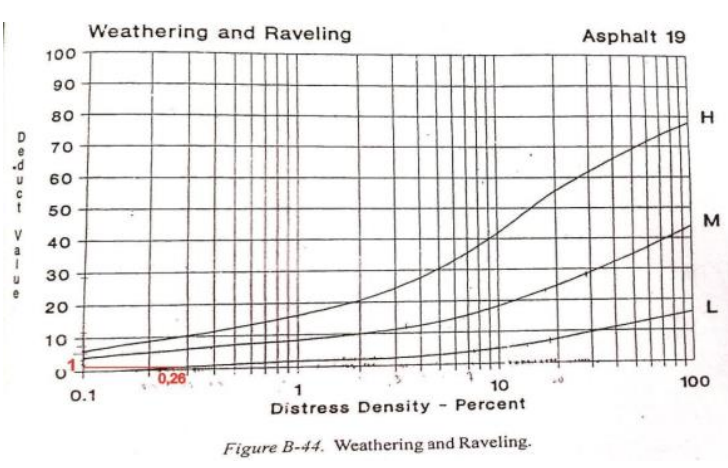

Gambar 2. Grafik Hubungan Kerapatan (\%) dengan DV

Setelah didapatkan nilai kerapatan $0,26 \%$ diterapkan pada sumbu horizontal kemudian ditarik ke atas sampai bertemu garis tingkat kerusakan L, setelah itu ditarik ke kiri sampai bertemu dengan sumbu vertikal. Maka didapatkan nilai DV untuk ruas $A$, unit sampel A1 dan pada kerusakan pelapukan dan butiran lepas (19) Rendah (L) adalah 1. Untuk ruas-ruas yang lain, dengan cara yang sama menentukan nilai DV dengan melihat grafik-grafik pada lampiran 2 sesuai jenis kerusakan. d. Menentukan Nilai Pengurang Terkoreksi Maksimum (CDV)

Ditentukan secara literasi sebagai berikut :

1. Menentukan nilai DV yang nilainya lebih besar 2 (untuk jalan dengan perkerasan). Misalnya pada unit sampel A1 didapat nilai: 21;1. Jadi $\mathrm{q}=1$ (nilai-nilai pengurang (DV) yang lebih kecil dari 2 tidak diperhitungkan).

2. Menentukan nilai pengurang total (TDV) dengan menambahkan seluruh nilai DV individual. Dalam data A1. TDV $=21+1=$ 22

3. Nilai CDV didapatkan dari grafik hubungan CDV sesuai gambar berikut.

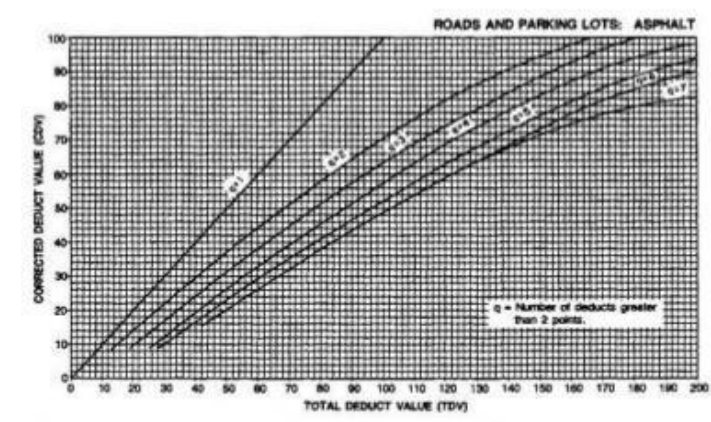

Gambar 3. Grafik Hubungan TDV dengan CDV

4. Melakukan iterasi sampai mendapatkan $q=1$ dengan cara. Mengurangi nilai DV yang nilainya lebih besar 2 diubah menjadi 2.

e. Nilai Hasil Analisis Pci

Maka PCI untuk setiap unit sampel dihitung dengan persamaan :

PCIs $=100-$ CDVmaks 
Dengan PCIs = PCI untuk setiap unit sampel atau unit penelitian, dan CDVmaks adalah nilai CDV tertinggi dari setiap unit sampel.

Nilai PCI perkerasan secara keseluruhan pada ruas jalan tertentu adalah :

PCIf $=($ Total PCIs $) / \mathrm{N}$

Dengan,

PCIf = nilai PCI rata-rata dari seluruh area penelitian

PCIs = nilai PCI untuk setiap unit sampel

$\mathrm{N}=$ Jumlah unit sampel

(1) Ruas Jalan Kedungpring - Sugio

Pada unit sampel A1 didapat nilai CDVmaks $=22$

$$
\begin{aligned}
& \text { PCIs }=100-\text { CDVmaks } \\
& \text { PCIs }=100-22 \\
& \text { PCIs }=78
\end{aligned}
$$

Jadi nilai PCI pada unit sampel A1 adalah 78. Cara yang sama dilakukan untuk unit sampel yang lain.

Nilai PCIf pada ruas jalan Kedungpring Sugio yaitu

$$
\begin{aligned}
& \text { PCIf }=539.52 / 10=53,952 \\
& \text { PCIf }=53,952
\end{aligned}
$$

Jadi Nilai PCIf pada ruas jalan Kedungpring - Sugio $=53,952$.
Tabel 2. Nilai PCI Ruas Jalan

Kedungpring - Sugio

\begin{tabular}{|c|c|c|c|}
\hline No. & Unit Sampel & CDVmaks & $\begin{array}{c}\text { Nilai PCI }_{\mathrm{s}} \\
(100 \text {-CDVmaks })\end{array}$ \\
\hline 1 & $\mathrm{~A} 1$ & 22 & 78 \\
\hline 2 & $\mathrm{~A} 2$ & 98 & 2 \\
\hline 3 & $\mathrm{~A} 3$ & 84.48 & 15.52 \\
\hline 4 & $\mathrm{~A} 4$ & 85 & 15 \\
\hline 5 & $\mathrm{~A} 5$ & 33 & 67 \\
\hline 6 & $\mathrm{~A} 6$ & 9 & 90.64 \\
\hline 7 & $\mathrm{~A} 7$ & 49 & 51 \\
\hline 8 & $\mathrm{~A} 8$ & 34 & 66 \\
\hline 9 & $\mathrm{~A} 9$ & 26 & 74 \\
\hline 10 & $\mathrm{~A} 10$ & 20 & 80 \\
\hline \multicolumn{5}{|c|}{ Jumlah $^{2}$} & 539.52 \\
\hline & PCI & & 53.952 \\
\hline
\end{tabular}

Sumber : Hasil Perhitungan

\section{Penentuan Nilai Kondisi Perkerasan}

Dari hasil penelitian menggunakan metode pci kerusakan yang paling dominan yaitu retak kulit buaya dengan total kerusakan 24,3 m2 dengan tingkat kerusakan "medium/sedang" dan untuk kerusakan lain dapat dilihat pada tabel 3. Di bawah ini.

Tabel 3. Rekapitulasi Kerusakan Perkerasan Ruas Jalan Kedungpring - Sugio (PCI)

\begin{tabular}{|c|l|c|c|}
\hline No. & \multicolumn{1}{|c|}{ Jenis Kerusakan } & $\begin{array}{c}\text { Tingkat } \\
\text { Kerusakan }\end{array}$ & $\begin{array}{c}\text { Total Kerusakan } \\
\left(\mathrm{m}, \mathrm{m}^{2}, \text { angka) }\right.\end{array}$ \\
\hline 1 & Retak Kulit Buaya (1) & Rendah (L) & $22.6 \mathrm{~m}^{2}$ \\
\hline 2 & Retak Kulit Buaya (1) & Sedang (M) & $24.3 \mathrm{~m}^{2}$ \\
\hline 3 & Retak Pinggir (7) & Sedang (M) & $10 \mathrm{~m}$ \\
\hline 4 & Jalur/Bahu Turun (9) & Rendah (L) & $9 \mathrm{~m}$ \\
\hline 5 & $\begin{array}{l}\text { Tambalan dan Tambalan Galian } \\
\text { Utilitas (11) }\end{array}$ & Sedang (M) & $2.4 \mathrm{~m}$ \\
\hline 6 & Lubang (13) & Rendah (L) & 4 \\
\hline 7 & Lubang (13) & Sedang (M) & 3 \\
\hline 8 & Sungkur (16) & Rendah (L) & $5 \mathrm{~m}^{2}$ \\
\hline 9 & Sungkur (16) & Sedang (M) & $1.25 \mathrm{~m}^{2}$ \\
\hline 10 & Retak Slip (17) & Sedang (M) & $0.075 \mathrm{~m}^{2}$ \\
\hline 11 & Pelapukan dan Butiran Lepas (19) & Rendah (L) & $23.42 \mathrm{~m}^{2}$ \\
\hline 12 & Pelapukan dan Butiran Lepas (19) & Sedang (M) & $5.5 \mathrm{~m}^{2}$
\end{tabular}

Sumber: Hasil Perhitungan, 2020 
Penelitian menggunakan Metode PCI hanya terdapat 8 jenis kerusakan yaitu Retak Kulit Buaya dengan tingkat kerusakan Low/Rendah (1L) dengan total kerusakan 22,6 m2 dan Medium/Sedang (1M) dengan total kerusakan 24,3 m2, Retak Pinggir (7M) dengan total kerusakan 10 m, Jalan/Bahu Turun (9L) dengan total kerusakan 9 m, Tambalan dan Tambalan Galian Utilitas (11M) dengan total kerusakan 2,4 m, Lubang (13L) dengan total kerusakan 4, Lubang (13M) dengan total kerusakan 3, Sungkur (16L) dengan total kerusakan $5 \mathrm{~m} 2$, Sungkur (16M) dengan total kerusakan 1,25 m2, Retak Slip (17M) dengan total kerusakan 0,075 m2, Pelapukan dan Butiran Lepas (19L) dengan total kerusakan 23,42 m2, Pelapukan dan Butiran Lepas (19M) dengan total kerusakan 5,5 m2.

Berdasarkan analisis data di atas menghasilkan Rating Kondisi Perkerasan yang sama pada masing-masing ruas. Nilai Kondisi Perkerasan dan Rating Kondisi Perkerasan masing-masing disajikan pada Tabel 4. berikut ini.
Tabel 4. Nilai Kondisi Perkerasan dan Rating Kondisi Perkerasan

\begin{tabular}{|c|c|c|c|}
\hline \multirow{2}{*}{ No. } & \multirow{2}{*}{ Ruas Jalan } & \multicolumn{2}{|c|}{ PCI } \\
\cline { 3 - 4 } & & $\begin{array}{c}\text { Nilai } \\
\text { PCI }\end{array}$ & Deskriptif \\
\hline 1 & Kedungpring - Sugio & 53,952 & Sedang \\
\hline
\end{tabular}

Sumber: Hasil perhitungan, 2020

Berdasarkan Tabel 5.2 Nilai Kondisi Perkerasan dan Rating kondisi Perkerasan pada ruas jalan Kedungpring - Sugio menghasilkan Rating Kondisi nilai perkerasan 4,5 termasuk dalam kondisi Sedang karena masuk kisaran angka 3 - 8 sedangkan menggunakan metode PCI menghasilkan Nilai PCI 53,952 termasuk dalam kondisi Sedang karena masuk kisaran angka 40 - 55.

\section{SIMPULAN}

Berdasarkan hasil penelitian dan analisis data didapat beberapa kesimpulan sebagai berikut ini.

1. Pada penelitian di ruas jalan Kedungpring - Sugio dengan menggunakan metode PCI (Pavement Condition Index) jenis kerusakan yang ada adalah retak kulit buaya, retak pinggir, jalur/bahu turun, tambalan dan tambalan galian utilitas, lubang, sungkur, retak slip dan pelapukan dan butiran lepas. Jenis kerusakan yang paling mendominasi adalah retak kulit buaya dengan total luas kerusakan 46,9 m2. 
2. Nilai kondisi perkerasan pada ruas jalan

Sugio - Kedungpring dengan

menggunakan metode PCI (Pavement

Condition Index) yaitu sebesar 53,952.

\section{DAFTAR PUSTAKA}

American Society for Testing and Materials. ASTM D5340-12. (2012). Standard Test Method for Airport Pavement Condition Index Surveys. United State: ASTM International.

Lukman, P.A., 2014, “Evaluasi Pekerasan Lentur Memakai Metode Pavement Condition Index (PCI) Berdasarkan Data Alat Hawkeye", Studi Kasus: Jalan Lingkar Nagrek Jawa Barat, Sistem dan Teknik Jalan Raya. Skripsi. ITB, Bandung.

Shahin, M. Y. (1994). Pavement Management for Airports, Roads, and Parking Lots. Chapman \& Hall. New York.

Sirait, A., Bernad, R., Syafaruddin, A. S., \& Sulandari, E. (2017). Analisa Kondisi Kerusakan Jalan Raya pada Lapisan Permukaan (Studi Kasus: Jalan Raya Desa Kapur, Desa Kapur, Kecamatan Sungai Raya, Kabupaten Kubu Raya, Provinsi Kalimantan Barat). (Doctoral dissertation, Tanjungpura University).

Suwardo dan Sugiharto, 2004, Tingkat Kerataan Jalan Berdasarkan Alat Rolling Straight Edge Untuk Mengestimasi Kondisi Pelayanan Jalan (PSI dan RCI), (Online):

(http://www.suwardo.staff.ugm.ac.id/artikel/Tingk at_kerataan.pdf. Diakses 17 Januari 2020) 